\title{
Which factors are associated with the prevalence of meniscal repair?
}

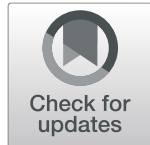

\author{
Xiaoxiao Song ${ }^{1}$, Dongyang Chen ${ }^{2}$, Xinsheng Qi ${ }^{1}$, Qing Jiang ${ }^{2}$ and Caiwei Xia ${ }^{1 *}$
}

\begin{abstract}
Purpose To investigate the potential factors associated with the prevalence of meniscal repair Methods Patients who received partial meniscectomy or meniscal repair in our institution from Jan 2015 to Dec 2019 were included in current study. The inclusion criteria were (1) meniscus tear treated using meniscectomy or repair, (2) with or without concomitant anterior cruciate ligament reconstruction, (3) not multiligamentous injury. Demographic data, including sex, age, body mass index (BMI), injury-to-surgery interval and intra-articular factors such as the location of injury, medial or lateral, ACL rupture or not and the option of procedure (partial meniscectomy or repair) were documented from medical records. Univariate analysis consisted of chi-square. Multivariate logistic regression was then performed to adjust for confounding factors.

Results 592 patients including 399 males and 193 females with a mean age of 28.7 years (range from 10 to 75 years) were included in current study. In the univariate analysis, male $(p=0.002)$, patients aged 40 years or younger $(p<0.001)$, increased weight ( $p=0.010)$, Posterior meniscus torn (0.011), concurrent ACL ruputure $(p<0.001)$, lateral meniscus $(p=0.039)$ and early surgery $(p<0.001)$ were all associated with the prevalence of meniscal repair. However, After adjusting for confounding factors, we found that age $(\mathrm{OR}, 0.35 ; 95 \% \mathrm{Cl}, 0.17-0.68, p=0.002), \mathrm{ACL}$ injury $(\mathrm{OR}, 3.76 ; 95 \% \mathrm{Cl}, 1.97-7.21, p<0.001)$, side of menisci $(\mathrm{OR}, 3.29 ; 95 \% \mathrm{Cl}, 1.43-7.55, p=0.005)$, site of tear $(\mathrm{OR}, 0.15 ; 95 \% \mathrm{Cl}, 0.07-0.32, p<0.001)$, and duration of injury $(\mathrm{OR}, 0.46 ; 95 \% \mathrm{Cl}, 0.28-0.82, p=0.008)$ were associated with the prevalence of meniscus repair.

Conclusions Meniscal tear in aged patients especially those with concomitant $A C L$ injury is likely to be repaired. Additionally, in order to increase the prevalence of repair and slow down progression of OA, the surgical procedure should be performed within two weeks after meniscus tear especially when the tear is located at lateral meniscal posterior.
\end{abstract}

Study design: Case-control study; level of evidence, 3.

Keywords: meniscal repair, meniscectomy, concurrent $A C L$ injury, age, duration of injury

\section{Introduction}

Meniscus is a vital intra-articular structure to maintain knee stability and to slow down the progression to osteoarthritis $(\mathrm{OA})[1,2]$. It also play an important role in load transmission, shock absorption and joint lubrication $[3,4]$. With the development of diagnostic techniques for meniscal injury, the volume of arthroscopic procedures to treat injuried meniscus dramatically

\footnotetext{
* Correspondence: njusummer@163.com

'Department of Orthopedics, Affiliated Taikang Xianlin Drum Tower Hospital, Medical school of Nanjing University, Nanjing, Jiangsu, P.R. China

Full list of author information is available at the end of the article
}

increased in recent years. Partial meniscectomy had been widely used for patients who underwent a failure of nonoperative treatment in early years $[5,6]$. However, with deep understanding of the biomechanical function of meniscus, surgeon realized that meniscectomy surgery could relieve pain and improve knee function at shortterm follow up, but the loss of meniscal tissue also accelerate the development of early $\mathrm{OA}$ in the future $[7,8]$. In comparison with partial meniscectomy, meniscus repair procedure can restore its biomechanical function and prevent the development of knee OA by preserving meniscal tissue at long-term follow up. In the above

C C The Author(s). 2021 Open Access This article is licensed under a Creative Commons Attribution 4.0 International License, which permits use, sharing, adaptation, distribution and reproduction in any medium or format, as long as you give appropriate credit to the original author(s) and the source, provide a link to the Creative Commons licence, and indicate if changes were made. The images or other third party material in this article are included in the article's Creative Commons licence, unless indicated otherwise in a credit line to the material. If material is not included in the article's Creative Commons licence and your intended use is not permitted by statutory regulation or exceeds the permitted use, you will need to obtain permission directly from the copyright holder. To view a copy of this licence, visit http://creativecommons.org/licenses/by/4.0/ The Creative Commons Public Domain Dedication waiver (http://creativecommons.org/publicdomain/zero/1.0/) applies to the data made available in this article, unless otherwise stated in a credit line to the data. 
setting, a consensus had been reached that meniscal tissue should be preserved as much as possible [9-11].

The surgeon would determine whether to repair the injuried meniscus for patients based on the following two criterions: the location of meniscal tear and the severity of meniscal injury. If the meniscal tear located in red-red zone or the remaining meniscal tissue is adequate, the repair procedure may be performed [12]. However we cannot give them an accurate answer, when patients consult about the surgical plan before operation as the severity and the vascularity of meniscus are subjective standards and was able to be precisely evaluated based on surgeon's experience under the arthroscope $[13,14]$. To our knowledge, studies tried to find factors associated with the prevalence of meniscus repair were rare. Thus, we performed this study to investigate the potential factors associated with the choice of repair procedure and to make the standards for repair surgery more specific. So that we can counsel patients about the options and expectations preoperatively. Additionally, identifying these factors can increase the prevalence of patients undergoing meniscal repair. We hypothesized that young patients with meniscal posterior horn tear are more likely to underwent repair surgery.

\section{Method}

Institutional review board approval was waived as no patients' private information was involved. 592 patients who received partial meniscectomy or repair in our institution from Jan 2015 to Dec 2019 by three high experienced surgeons were included in current study. The inclusion criteria were (1) meniscus tear treated using meniscectomy or repair, (2) with or without concomitant anterior cruciate ligament reconstruction, (3) not multiligamentous injury. Demographic data, including sex, age, body mass index (BMI), injury-to-surgery interval and intra-articular factors such as the location of injury, medial or lateral, ACL rupture or not and the option of procedure (partial meniscectomy or repair) were documented from medical records. Age was divided into older group $(>40)$ and younger group $(\leq 40)$, the duration from injury to surgery was defined as delayed group ( $>2$ weeks) and early group ( $\leq 2$ weeks), BMI was divided into three groups $\left(\leq 24 \mathrm{Kg} / \mathrm{m}^{2}, 24-27 \mathrm{Kg} / \mathrm{m}^{2}\right.$, and $\geq 27 \mathrm{Kg} / \mathrm{m}^{2}$ ),

The meniscal injury was determined by clinical examination, magnetic resonance imaging (MRI) and intraoperative findings. Surgical procedure were performed by three experienced surgeons (being numbered as 1,2 and 3 , respectively) and the procedure was uniform. Anterolateral and anteromedial knee portals were utilized for all patients. Under arthroscopy, the meniscus tear patterns, the site and the potential vascularity were directly seen by the surgeons. Then the surgeon would determine a suitable procedure for each patient based on the following standards: (1) the location of meniscal tear; (2) the severity of meniscal injury. Meniscal repair was implemented through all-inside technique using meniscal repair device (Fast-Fix; Smith \& Nephew) for all patients with meniscal posterior, body or anterior tear. According to the length of tear, one to seven sutures were needed. When repair was not viable, injuried meniscus will be trimmed until a stable peripheral rim was achieved. In the case of a concurrent ACL injury, the ACL reconstruction will be performed firstly by using peroneal longus tendon as graft.

\section{Statistical analysis}

Statistical analyses were achieved by using the SPSS, version 23.0 (SPSS Inc., Chicago, IL, USA). To assess association between demographic data and the prevalence of partial meniscectomy procedure, chi-squared test were used. In the multivariate analysis, binary regression were used to identify the independent variables for meniscal partial meniscectomy. A p value less than 0.05 were considered statistical significant.

\section{Results}

From Jan 2015 to Nov 2019, 592 patients including 399 males and 193 females with a mean age of 28.7 years (range from 10 to 75 years) were included in current study. Of these patients, 368 patients underwent concomitant ACL reconstruction, 224 patients underwent isolated meniscal surgery. Partial meniscectomy was performed on 346 patients, the remaining 246 patients received meniscus repair operation (Fig. 1). Those demographic baseline data were shown in Table 1.

In the univariate analysis, seven variables were found to be associated with the prevalence of meniscus repair. male patients $(p=0.002)$, younger than 40 years $(p<$ $0.001)$, increasing of body weight $(p=0.010)$, Posterior meniscus torn and multiple site torn injury $(p=0.011)$, with concurrent ACL ruputure $(p<0.001)$, performing surgery within two weeks after injury $(p<0.001)$, and lateral or both sides injury $(p=0.039)$. Detailed data are displayed in Table 1.

Then, these variables were analyzed in multivariate logistic regression model. After adjusting for confounding factors, we found that age (OR, 0.35; 95\% CI, $0.17-0.68$, $p=0.002)$, ACL injury (OR, 3.76; 95\% CI, $1.97-7.21, p$ $<0.001$ ), side of menisci (OR, 3.29; 95\% CI, $1.43-7.55$, $p=0.005)$, site of tear (OR, 0.15; 95\% CI, $0.07-0.32, p$ $<0.001$ ), and duration of injury (OR, 0.46; $95 \% \mathrm{CI}, 0.28$ $-0.82, p=0.008)$ were associated with the prevalence of meniscus repair (Table 2). 


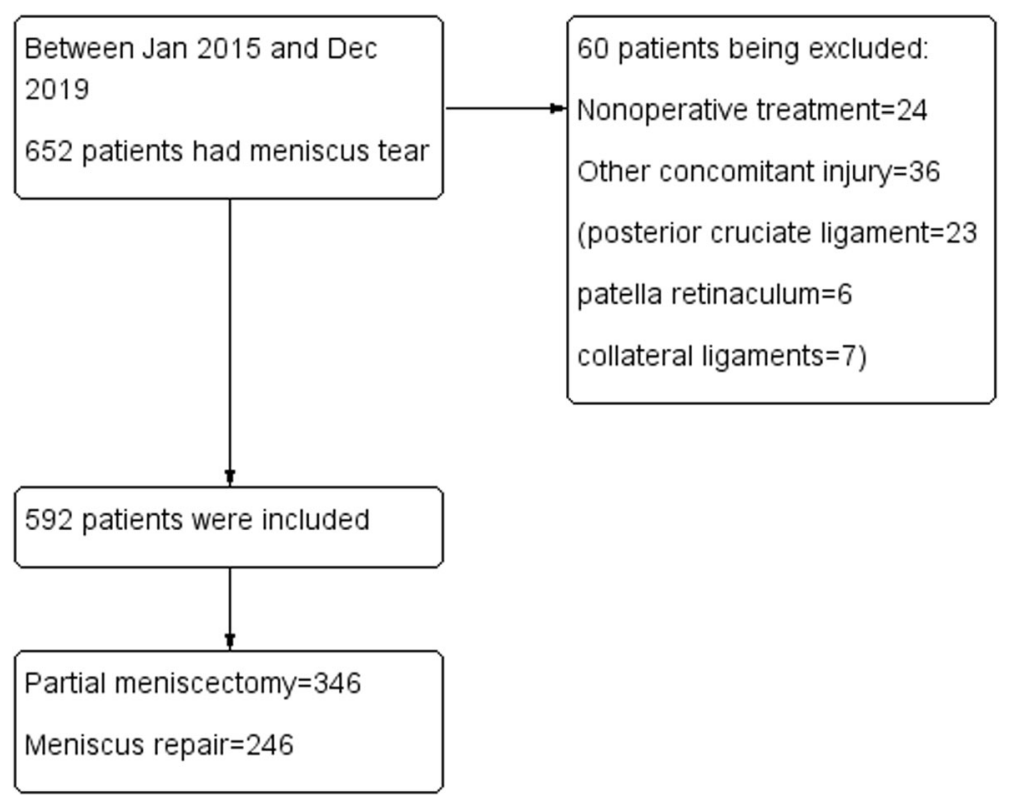

Fig. 1 Flowchart of included participants

\section{Discussion}

The most important findings of current study were that younger age, early arthroscopic surgery $(<2$ weeks), lateral meniscus tear, posterior horn tear and accompanying with ACL injury were associated with the prevalence of meniscal repair surgery.

The clinical outcomes between partial meniscectomy and meniscal repair has been hotly debated in recent years. In a study performed by Kyu et al [15], they observed the difference of patients-reported outcomes among patients who had underwent meniscectomy or repair for at least 10 years follow-up and claimed that meniscal repair had a superior clinical outcomes. Stein et al [16] evaluated the rate of return to sports in athletes and found that patients underwent meniscal repair had a higher rate of return to sports (96.15\%) comparing with those underwent partial meniscectomy (50\%) at 8.8-year follow-up. While the re-operation rates of meniscal repair was likely to be higher than that of meniscectomy at short-term follow-up [17]. Neverthless, given the increased risk of partial meniscectomy predisposing patients to early onset degenerative changes, preversation of meniscal tissue should be attempted whenever possible [9-11]. However, to our knowledge, no study was conducted to assess the potential factors associated with the prevalence of meniscal repair. In this setting, we performed this study.

The influence of age on the clinical outcomes after arthroscopic meniscal repair have been widely reported in previous literature. Mike et al [18] found that younger age could improve the knee function and enhanced the healing rate of repaired meniscus significantly which was consistent with another study [19]. However, substantial articles also shown an opposite conclusions. In a respective cohort study with 16-years follow-up, Steadman et al [20] found that the failure rate of meniscus repair, knee function and patient satisfaction were not significant in patients who are 40 years or younger and older than 40 years. Their findings were supported by Sarah et al [21] and Shane et al [22]. In current study, surgeons tend to perform meniscus repair for younger patients ( $\leq 40$ years). Michela et al [23]. found that the meniscal fibrocartilage became disrupt and proteoglycan content increased in those patients with OA (mean age: 72) and concluded that age was the strongest factor determining post-operative outcome. Additionally, the high possibilty of an early onset of OA when meniscal tissue is resected totally or partially also makes surgeons worried.

In our study, 472/512 (84.5\%) traumatic meniscus tear were accompanyed by a concurrent ACL rupture which was similar to other articles' results [24]. We found that ACL injury was the most important factor associated with the prevalence of meniscal repair. Many articles had reported a higher healing rate in patients undergoing a concomitant ACL reconstruction compared with those receiving isolated meniscus surgery [24-26]. They claimed that the intra-articular growth factors in bleeding from tunnels created an ideal enviroment for meniscus healing $[27,28]$. Besides, most of these meniscis tear accompanying with ACL injury were sports-related which was more common among younger patients. The above two reasons may be explained for the popularity of meniscus repair in patients having ACL injury concomitnatly. 
Table 1 Demographic baseline data

\begin{tabular}{|c|c|c|c|}
\hline & Partial meniscectomy (\%) & Repair (\%) & $P$-value \\
\hline Gender & & & 0.002 \\
\hline male & $216(54.1)$ & $183(45.9)$ & \\
\hline female & $130(67.4)$ & $63(32.6)$ & \\
\hline Age & & & $<0.001$ \\
\hline$\leq 40$ & $213(50.1)$ & $212(49.9)$ & \\
\hline$>40$ & $133(79.6)$ & $34(20.4)$ & \\
\hline Weight & & & 0.010 \\
\hline$\leq 60$ & $75(66.4)$ & 38 (33.6) & \\
\hline $60-90$ & $246(58.3)$ & $176(41.7)$ & \\
\hline$\geq 90$ & $20(40.8)$ & $29(59.2)$ & \\
\hline BMI & & & 0.544 \\
\hline$\leq 24$ & $170(60.3)$ & $112(39.7)$ & \\
\hline $24-27$ & $104(58.4)$ & $74(41.6)$ & \\
\hline$\geq 27$ & $67(54.5)$ & $56(45.5)$ & \\
\hline Site of tear & & & 0.011 \\
\hline Multiple & $40(55.6)$ & $32(44.4)$ & \\
\hline Anterior & $23(76.7)$ & $7(23.3)$ & \\
\hline Body & $43(69.4)$ & 19 (30.6) & \\
\hline Posterior & $114(51.8)$ & $106(48.2)$ & \\
\hline$A C L$ injury & & & $<0.001$ \\
\hline Yes & $160(43.5)$ & $208(56.5)$ & \\
\hline No & $186(83.0)$ & $38(17.0)$ & \\
\hline Duration of injury & & & $<0.001$ \\
\hline$\leq 2$ weeks & $59(39.3)$ & $91(60.7)$ & \\
\hline$>2$ weeks & $287(60.9)$ & $155(35.1)$ & \\
\hline Laterality of meniscus & & & 0.039 \\
\hline Lateral & $170(58.8)$ & $119(41.2)$ & \\
\hline Medial & $132(62.9)$ & $78(37.1)$ & \\
\hline Both & $44(47.3)$ & $49(52.7)$ & \\
\hline Surgeons & & & 0.211 \\
\hline 1 & $141(58.5)$ & $100(41.5)$ & \\
\hline 2 & 75 (57.3) & $56(42.7)$ & \\
\hline 3 & $130(59.1)$ & $90(40.9)$ & \\
\hline
\end{tabular}

Table 2 Multivariable analysis of factors associated with the prevalence of meniscal repair

\begin{tabular}{llll}
\hline & Regression coefficient & $\mathbf{9 5 \% C l}$ & $\boldsymbol{P}$-value \\
\hline Gender & 1.14 & 0.67 to 1.96 & $\mathrm{~ns}$ \\
Age & 0.35 & 0.17 to 0.68 & 0.002 \\
Weight & 1.03 & 0.55 to 1.93 & $\mathrm{~ns}$ \\
Site of tear & 0.15 & 0.07 to $0.32<0.001$ \\
ACL injury & 3.76 & 1.97 to $7.21<0.001$ \\
Duration of injury & 0.46 & 0.28 to 0.82 & 0.008 \\
Laterality of meniscus & 3.29 & 1.43 to 7.55 & 0.005 \\
\hline
\end{tabular}

The association between BMI and the clinical outcomes of meniscal repair had been widely studied in previous literature. In a meta-analysis [29], the authors concluded that the failure rate of repair surgery was not significant difference among patients with high BMI or low BMI. In another study, BMI was found to be inversely correlated with IKDC and Tegner activity level scores. In our study [30], we found that when performing meniscus repair surgery, surgeons may not consider patients' BMI as a contraindication for this surgery, but high body weight will be. We speculated that the large body weight could result in a high stress on joint and 
may consequently lead to serious meniscus injury but BMI can be influenced by patients' height.

Nonoperative treatment was commonly recommended to patients with degenerative meniscal injury. Partial meniscectomy or meniscus repair will be suggested when meniscal symptoms, including pain and knee locking cannot be relieved after a two-week conservative treatment in our institution. Haroon et al [24] found that the failure rate of meniscal repair was lower if meniscus is repaired within 6weeks in those patients acommpanying by ACL injury. However, we found that when arthroscopic surgery was delayed to two weeks later after injury, the ratio of undergoing meniscal repair will be reduced significantly. Meniscus is the second knee stabilizer. The meniscus tear will become more and more serious, when meniscal surgery was postponed especially when ACL deficient $[31,32]$. We speculated that the severely damaged meniscus may influence surgeons' decisions on meniscal repair as its poor healing potential.

As we all know, meniscus are classified as three zone, that is the white-white zone, white-red zone and red-red zone according to the vascularity [17]. Theoretically, tear within the vascular zone have a higher healing rate comparing with those in avascular zone $[17,24,29]$. In a study performen by Zhu et al [33]. found that human cartilage-derived morphogenetic protein-2 (hCDMP-2) growth factor could promote meniscal fibrocartilage healing by regenerating fibrocartilage-like tissue. The tissue in vascular zone was regenerated more rapidly than that in the avascular zone. In another study [34], the authors concluded that tear in red-red zone were more appropriate to be repaired as the higher healing rate. Theoretically, the meniscal vascularity is a vital factor that may affect surgeon's treatment options. However, in our study, we did not evaluate the influence of tear zones on the prevalence of repair as they were not recorded. Some authors believed that the posterior horn root tear should be repaired whenever possible, because detachment of posterior root can disrupt continuity of the circumferential fibers and lead to loss of hoop tension $[15,30]$. We also observed that surgeons tend to repair meniscal posterior horn.

No consensus being reached on whether the side of repair have differential influence on the clinical outcomes and the failure rate [29]. Some studies found lateral meniscal repair had a higher success rate [30], some other articles hold an opposite opinion, while much more literature shown that the the failure rate was not associated with the side of repair [29]. In current study, those patients with lateral meniscus tear and both sides injury were more likely to receive meniscal repair. The possible explainations for this finding may be that lateral meniscus injury was easy to repair with " 4 " character sign and both sides injury mean the tear was serious.

Despite many factors had been studied and shown to be associated with the high failure rate of maniscal repair or partial meniscectomy, whether they can affect surgeons' decision on treatment options and which will affect have not yet been evaluated. In current study, we found that aged patients especially those with concomitant ACL injury were more likely to receive maniscal repair. Additionally, in order to increase the prevalence of repair and slow down progression of $\mathrm{OA}$, the surgical procedure should be performed within two weeks after meniscus tear. Lateral meniscal posterior horn injury have a higher opportunity for meniscus repair.

However, our study have some limitations. Firstly, tear zone of meniscus should be an important predictive factor for treatment options, but we failed to assess it because of data loss. More study is needed, in the future, to investigate whether meniscal tear within the red-red zone is more likely to be repaired compared with those within white-white zone. Secondly, the data in this study were collected from a single medical center in China. Thus,more studies are needed in the future to investigate the relationship between patient-related factors and the prevalence of meniscal repair. Finally, option bias may exists because three different high experienced surgeons performed all arthroscopic meniscal operation, however, we believed this can reflect the realistic clinical issue.

Conclusion Patients should be informed that their meniscus are more likely to be repaired if they are young and operation is performed within 2 weeks after injury, and the meniscus tear is located at lateral meniscal posterior horn especially with concomitant ACL injury.

\section{Abbreviations}

ACL: Anterior cruciate ligament; BMI: Body mass index; MRI: Magnetic resonance imaging

\section{Acknowledgements \\ None}

\section{Authors' contributions}

XXS participated in the design of the study, wrote the manuscript and performed the study, CWX and XXS collected and analyzed the data. DYC and QJ and XSQ designed and supervised the entire study. XXS was a major contributor in writing the manuscript. All authors read and approved the final manuscript.

\section{Funding}

Clinical Research Project (TKKYLC20211203) supported this work

\section{Availability of data and materials}

The datasets used and/or analyzed during the current study will be available from author XXS on a reasonable request and no material or illustrations have been previously published 


\section{Declarations}

\section{Ethics approval and consent to participate}

No patients' private information is involved. Therefore ethics approval is not needed from our Research Ethics Committee and consent for participation was waived.

\section{Consent for publication}

Not applicable

\section{Competing interests}

The authors declare that no benefits in any form have been received or will be received from a commercial party related directly or indirectly to the subject of this article.

\section{Author details}

'Department of Orthopedics, Affiliated Taikang Xianlin Drum Tower Hospital, Medical school of Nanjing University, Nanjing, Jiangsu, P.R. China. ${ }^{2}$ Department of Sports Medicine and Adult Reconstructive Surgery, Nanjing Drum Tower Hospital, School of Medicine, Nanjing University, 321

Zhongshan Road, Nanjing 210008, Jiangsu, PR China.

\section{Received: 17 October 2020 Accepted: 22 February 2021}

\section{Published online: 22 March 2021}

\section{References}

1. Verdonk R, Madry H, Shabshin N, Dirisamer F, Peretti GM, Pujol N, Spalding $T$, Verdonk $P$, Seil $R$, Condello $V$, et al. The role of meniscal tissue in joint protection in early osteoarthritis. Knee Surg Sports Traumatol Arthrosc. 2016; 24(6):1763-74

2. Gupta R, Kapoor A, Mittal N, Soni A, Khatri S, Masih GD. The role of meniscal tears and meniscectomy in the mechanical stability of the anterior cruciate ligament deficient knee. Knee. 2018;25(6):1051-6.

3. Wu IT, Hevesi M, Desai VS, Camp CL, Dahm DL, Levy BA, Stuart MJ, Krych AJ. Comparative Outcomes of Radial and Bucket-Handle Meniscal Tear Repair: A Propensity-Matched Analysis. Am J Sports Med. 2018;46(11):2653-60.

4. Karia M, Ghaly Y, Al-Hadithy N, Mordecai S, Gupte C. Current concepts in the techniques, indications and outcomes of meniscal repairs. Eur J Orthop Surg Traumatol. 2019;29(3):509-20.

5. Sofu H, Oner A, Camurcu Y, Gursu S, Ucpunar H, Sahin V. Predictors of the Clinical Outcome After Arthroscopic Partial Meniscectomy for Acute Trauma-Related Symptomatic Medial Meniscal Tear in Patients More Than 60 Years of Age. Arthroscopy. 2016;32(6):1125-32.

6. Stein JM, Yayac M, Conte EJ, Hornstein J. Treatment Outcomes of Meniscal Root Tears: A Systematic Review. Arthrosc Sports Med Rehabil. 2020;2(3): e251-61.

7. Svantesson E, Cristiani R, Hamrin Senorski E, Forssblad M, Samuelsson K, Stalman A. Meniscal repair results in inferior short-term outcomes compared with meniscal resection: a cohort study of 6398 patients with primary anterior cruciate ligament reconstruction. Knee Surg Sports Traumatol Arthrosc. 2018;26(8):2251-8.

8. Haviv B, Bronak S, Kosashvili Y, Thein R. Which patients are less likely to improve during the first year after arthroscopic partial meniscectomy? A multivariate analysis of 201 patients with prospective follow-up. Knee Surg Sports Traumatol Arthrosc. 2016:24(5):1427-31.

9. Zimmerer A, Sobau C, Nietschke R, Schneider M, Ellermann A. Long-term outcome after all inside meniscal repair using the FasT-Fix system. J Orthop. 2018;15(2):602-5

10. Fuchs A, Kloos F, Bode G, Izadpanah K, Sudkamp NP, Feucht MJ. Isolated revision meniscal repair - failure rates, clinical outcome, and patient satisfaction. BMC Musculoskelet Disord. 2018;19(1):446.

11. Billieres J, Pujol N, and the UCoE: Meniscal repair associated with a partial meniscectomy for treating complex horizontal cleavage tears in young patients may lead to excellent long-term outcomes. Knee Surg Sports Traumatol Arthrosc 2019, 27(2):343-348.

12. Kramer DE, Kalish LA, Martin DJ, Yen YM, Kocher MS, Micheli LJ, Heyworth BE: Outcomes After the Operative Treatment of Bucket-Handle Meniscal Tears in Children and Adolescents. Orthop J Sports Med 2019, 7(1): 2325967118820305.

13. Felli L, Garlaschi G, Muda A, Tagliafico A, Formica M, Zanirato A, AlessioMazzola M. Comparison of clinical, MRI and arthroscopic assessments of chronic ACL injuries, meniscal tears and cartilage defects. Musculoskelet Surg. 2016;100(3):231-8.

14. Bari AA, Kashikar SV, Lakhkar BN, Ahsan MS. Evaluation of MRI versus arthroscopy in anterior cruciate ligament and meniscal injuries. J Clin Diagn Res. 2014:8(12):RC14-8.

15. Chung KS, Ha JK, Ra HJ, Yu WJ, Kim JG. Root Repair Versus Partial Meniscectomy for Medial Meniscus Posterior Root Tears: Comparison of Long-term Survivorship and Clinical Outcomes at Minimum 10-Year Followup. Am J Sports Med. 2020:48(8):1937-44.

16. Paxton ES, Stock MV, Brophy RH. Meniscal repair versus partial meniscectomy: a systematic review comparing reoperation rates and clinical outcomes. Arthroscopy. 2011;27(9):1275-88

17. Patel NM, Mundluru SN, Beck NA, Ganley TJ: Which Factors Increase the Risk of Reoperation After Meniscal Surgery in Children? Orthop J Sports Med 2019, 7(5):2325967119842885.

18. Tengrootenhuysen M, Meermans G, Pittoors K, van Riet R, Victor J. Longterm outcome after meniscal repair. Knee Surg Sports Traumatol Arthrosc 2011:19(2):236-41.

19. Lyman S, Hidaka C, Valdez AS, Hetsroni I, Pan TJ, Do H, Dunn WR, Marx RG. Risk factors for meniscectomy after meniscal repair. Am J Sports Med. 2013:41(12):2772-8.

20. Steadman JR, Matheny LM, Singleton SB, Johnson NS, Rodkey WG, Crespo B, Briggs KK. Meniscus suture repair: minimum 10-year outcomes in patients younger than 40 years compared with patients 40 and older. Am J Sports Med. 2015:43(9):2222-7.

21. Poland S, Everhart JS, Kim W, Axcell K, Magnussen RA, Flanigan DC. Age of 40 Years or Older Does Not Affect Meniscal Repair Failure Risk at 5 Years. Arthroscopy. 2019;35(5):1527-32.

22. Rothermel SD, Smuin D, Dhawan A. Are Outcomes After Meniscal Repair Age Dependent? A Systematic Review. Arthroscopy. 2018;34(3):979-87.

23. Tsujii A, Nakamura N, Horibe S. Age-related changes in the knee meniscus. Knee 2017:24(6):1262-70.

24. Majeed H, Karuppiah S, Sigamoney KV, Geutjens G, Straw RG. All-inside meniscal repair surgery: factors affecting the outcome. J Orthop Traumatol. 2015;16(3):245-9.

25. Matsushita T, Nagai K, Araki D, Tanaka T, Matsumoto T, Nishida K, Kurosaka M, Kuroda R. Factors associated with the status of meniscal tears following meniscal repair concomitant with anterior cruciate ligament reconstruction. Connect Tissue Res. 2017;58(3-4):386-92

26. Chahla J, Dean CS, Matheny LM, Mitchell JJ, Cinque ME, RF LP. Outcomes of Inside-out Meniscal Repair in the Setting of Multiligament Reconstruction in the Knee. Am J Sports Med. 2017:45(9):2098-104.

27. Uzun E, Misir A, Kizkapan TB, Ozcamdalli M, Akkurt S, Guney A: Factors Affecting the Outcomes of Arthroscopically Repaired Traumatic Vertical Longitudinal Medial Meniscal Tears. Orthop J Sports Med 2017, 5(6):2325967117712448.

28. Tsujii A, Yonetani Y, Kinugasa K, Matsuo T, Yoneda K, Ohori T, Hamada M. Outcomes More Than 2 Years After Meniscal Repair for Radial/Flap Tears of the Posterior Lateral Meniscus Combined With Anterior Cruciate Ligament Reconstruction. Am J Sports Med. 2019:47(12):2888-94.

29. Yeo DYT, Suhaimi F, Parker DA: Factors Predicting Failure Rates and PatientReported Outcome Measures After Arthroscopic Meniscal Repair. Arthroscopy 2019, 35(11):3146-3164 e3142.

30. Krych AJ, Bernard CD, Kennedy NI, Tagliero AJ, Camp CL, Levy BA, Stuart MJ: Medial Versus Lateral Meniscus Root Tears: Is There a Difference in Injury Presentation, Treatment Decisions, and Surgical Repair Outcomes? Arthroscopy 2020, 36(4):1135-1141.

31. Stone JA, Perrone GS, Nezwek TA, Cui Q, Vlad SC, Richmond JC, Salzler MJ. Delayed ACL Reconstruction in Patients $>/=40$ Years of Age Is Associated With Increased Risk of Medial Meniscal Injury at 1 Year. Am J Sports Med. 2019;47(3):584-9.

32. Chen $\mathrm{KH}$, Chiang ER, Wang HY, Ma HL. Correlation of Meniscal Tear with Timing of Anterior Cruciate Ligament Reconstruction in Patients without Initially Concurrent Meniscal Tear. J Knee Surg. 2019;32(11):1128-32.

33. Zhu WH, Wang YB, Wang L, Qiu GF, Lu LY. Effects of canine myoblasts expressing human cartilagederived morphogenetic protein2 on the repair of meniscal fibrocartilage injury. Mol Med Rep. 2014;9(5):1767-72.

34. Pillai MM, Gopinathan J, Selvakumar R, Bhattacharyya A. Human Knee Meniscus Regeneration Strategies: a Review on Recent Advances. Cur Osteoporos Rep. 2018;16(3):224-235c

\section{Publisher's Note}

Springer Nature remains neutral with regard to jurisdictional claims in published maps and institutional affiliations. 